\title{
Social capital and life satisfaction: a cross- sectional study on persons with musculoskeletal impairments in Hanoi, Vietnam
}

Kyo Takahashi ${ }^{1}$, Nguyen Thi Minh Thuy ${ }^{2}$, Krishna C Poudel ${ }^{1}$, Kayako Sakisaka ${ }^{1}$, Masamine Jimba ${ }^{1}$ and Junko Yasuoka ${ }^{1 *}$

\begin{abstract}
Background: Social capital has been recognized as a major social determinant of health, but less attention has been given to social capital of persons with musculoskeletal impairments. The present study aimed to explore the associations between social capital and life satisfaction of persons with musculoskeletal impairments in Hanoi, Vietnam.

Methods: A cross-sectional study was conducted in Hanoi, Vietnam. From June to July 2008, we collected data from 136 persons with musculoskeletal impairments who belonged to disabled people's groups. Social capital was measured using a short version of the Adapted Social Capital Assessment Tool that included group membership, support from groups, support from individuals, citizenship activities, and cognitive social capital. Life satisfaction was measured using the Satisfaction with Life Scale. As possible confounding factors, we measured socio-economic factors and disability-related factors such as activities of daily living.

Results: After controlling for confounding effects, group membership remained significantly associated with the level of life satisfaction reported by the persons with musculoskeletal impairments. In particular, being an active member of two or more groups was associated with higher life satisfaction. In contrast, other components of social capital such as citizenship activities and cognitive social capital were not significant in the multiple regression analysis of this study.

Conclusions: The findings suggest the importance of considering an active participation in multiple groups toward the enhancement of the life satisfaction among persons with musculoskeletal impairments. To encourage persons with musculoskeletal impairments to have multiple active memberships, their access to groups should be facilitated and enhanced.
\end{abstract}

\section{Background}

As the number of persons with disabilities increases, the social aspects of disability have gained substantial attention [1]. Disability is not just a negative consequence of a medical condition any longer but a complex situation with medical and social factors [2]. For example, 'full and effective participation and inclusion in society' is one of the main principles of the Convention on the Rights of Persons with Disabilities [3]. The state of

\footnotetext{
* Correspondence: jyasuoka@post.harvard.edu

'Department of Community and Global Health, Graduate School of

Medicine, the University of Tokyo, 7-3-1 Hongo, Bunkyo-ku, Tokyo, Japan Full list of author information is available at the end of the article
}

persons with disabilities, however, varies by country [4]. The World Health Organization [5] has estimated that approximately 80 percent of persons with disabilities live in developing countries where the social aspects of disability still do not receive sufficient attention.

Social capital has been recognized as a major social determinant of health [6,7]. While the definition of social capital varies, Robert Putnam's definition [8] has been well accepted: 'features of social organization, such as trust, norms, and networks that can improve the efficiency of society by facilitating coordinating actions' [9]. However, social capital has not been investigated only as a social cohesion but with certain attributes of

\section{() Biomed Central}


individual such as social support and social network [7]. For example, social capital has been divided into different types, with a common distinction being between structural and cognitive social capital [10]. Structural social capital, such as networks, is relatively tangible. On the other hand, cognitive social capital is invisible since it is measured by individuals' perceptions of connectedness in their community. The characteristics of these two types of social capital are dissimilar, but they robustly interact with each other [11]. In the health field, social capital has been studied mainly in the general population. For example, analyzing the data of 167,259 individuals in the United States, Kawachi et al. [12] revealed that low social capital was associated with self-rated poor health. Similarly, Helliwell and Putnam [13] confirmed that a strong link exists between social capital and subjective well-being in North America. Even in an ecological study, Bjornskov [14] found social capital to be a powerful factor in explaining the differences in levels of happiness among European countries. Despite the rapid accumulation of social capital studies, less attention has been paid to persons with disabilities who tend to be socially isolated.

Life satisfaction is one aspect of subjective well-being, and it can be a useful measure in health studies especially for persons with physical disabilities. Pavot and Diener [15] describe life satisfaction as 'a conscious cognitive judgment of one's life in which the criteria for judgment are up to the person.' In this sense, life satisfaction does not differentiate persons by physical ability or disability. In other words, life satisfaction can be properly measured regardless of whether persons are physically disabled. Despite the ample availability of instruments, most studies of the life satisfaction have been conducted in developed countries $[16,17]$. The various populations were targeted in those studies; however, the studies of the life satisfaction of persons with disabilities have been limited only to persons with spinal cord injuries [18-20].

Vietnam is a developing country experiencing rapid economic growth. It has sought to improve the social lives of persons with disabilities by promoting their participation in social activities. For example, the Hanoi Disabled People Association (DP Hanoi) was established in 2006 as the first legal organization of persons with disabilities. DP Hanoi consists of 22 various disabled people's groups whose members are persons with visual, hearing, or mobility disabilities. It has enlightened the human rights of persons with disabilities in Vietnam by putting up a number of events and has consistently encouraged persons with disabilities to actively participate in society by providing various opportunities including the useful information of employment. Although the social aspect of disability receives increasing attention elsewhere [21], little evidence regarding it is available from Vietnam and other developing countries.

Therefore, this study aimed to explore the association between social capital and life satisfaction of persons with physical disabilities in Hanoi, Vietnam.

\section{Methods \\ Participants}

In Vietnam, the number of persons with disabilities was estimated approximate 5,333,000 which was equivalent to $6.4 \%$ of the total population [4]. We targeted persons with disabilities who belonged to disabled people's groups in Hanoi, the capital city of Vietnam. The Ordinance on Disabled Persons in Vietnam defines persons with disabilities as those having 'defective of one or many parts of the body or functions which are shown in different forms of disability, and which reduce the capability of activity and cause many difficulties to work, life and studies [4].' The distribution of general types of disability in Vietnam was reported as follows: mobility $42 \%$, learning $23 \%$, hearing $22 \%$ and visual $7 \%$ in 2006 [22]. We particularly focused on musculoskeletal impairment, which could cause mobility disability and physically limit social participation.

Inclusion criteria included having one or more musculoskeletal impairments, belonging to a disabled people's group under DP Hanoi, and being over 18 years old. We excluded those with other kinds of disabilities such as visual, hearing, and intellectual disabilities.

Among 22 disabled people's groups under DP Hanoi, nine groups were run by and for persons with musculoskeletal impairments. Two hundred and thirty-two members were registered in the nine groups. We tried to contact all of them in the regular or special meetings of each group from June to July 2008. After the meetings, the group leaders contacted those who did not attend the meetings and recruited them individually. In the end, we contacted 152 members (65.5\%) and 136 of them $(58.6 \%)$ agreed to participate in this study and met the criteria.

We obtained ethical approval from the ethical committee of the University of Tokyo. We explained the study objectives to all participants, and obtained their informed consent. Two authors (KT and NTMT) supervised all aspects of the data collection.

\section{Instruments}

We developed a self-administered questionnaire and had it translated from English into Vietnamese. The questionnaire was developed to measure social capital, life satisfaction, socio-economic factors, and disabilityrelated factors. In February 2008, we pre-tested the questionnaire among 21 persons with musculoskeletal 
impairments in targeted disabled people's groups to enhance its validity and reliability. For those who could not write, we allowed them to be physically supported by personal assistants with their verbal responses.

\section{Social capital}

We used a short version of the Adapted Social Capital Assessment Tool (SASCAT) to measure the individual structural and cognitive social capital of the participants (Table 1). SASCAT was developed for use in studies in developing countries, including Vietnam [23], as a modified version of the Adapted Social Capital Assessment Tool [24]. Structural social capital was measured with five questions about 'group membership,' 'support from groups,' 'support from individuals,' 'joining together with other community members,' and 'talking with a local authority or government organization.' In the question regarding 'group membership,' we measured self-defined active participation. Those who did not actively participate in their group were not classified as active members regardless of their membership. Cognitive social capital was measured with four questions about 'trust,' 'social harmony,' 'sense of belonging,' and 'sense of fairness.' We defined 'community' as the official commune which was clearly understood as a geographical community in Vietnam [9,25].

\section{Life satisfaction}

To measure life satisfaction, we used the Satisfaction with Life Scale (SWLS), which was developed by Diener et al. [26]. A series of validation studies demonstrated satisfactory content and predictive validity among various age groups [26,27]. SWLS has been used for a wide variety of study purposes [28]. SWLS consists of five Likert items with seven response levels ranging from 'strongly disagree $(=1)$ ' to 'strongly agree $(=7)$.' The items were: 1) In most ways my life is close to ideal, 2) The conditions of my life are excellent, 3) I am satisfied

Table 1 Short version of Adapted Social Capital Assessment Tool (SASCAT)

\begin{tabular}{|c|c|c|}
\hline \multicolumn{2}{|l|}{ Questions } & Coding \\
\hline \multicolumn{2}{|l|}{ Group membership } & 0 \\
\hline \multirow{2}{*}{\multicolumn{2}{|c|}{ 1. In the last 12 months have you been an active member of any of the following types of groups in your community? }} & 1 \\
\hline & & 2 or more \\
\hline$\gg$ Work related/trade union & $\gg$ Credit/funeral group & \\
\hline$\gg$ Community association/co-op & $>$ Sports group & \\
\hline$>$ Political group & $\gg$ Others: specify & \\
\hline \multicolumn{3}{|l|}{$\gg$ Religious group } \\
\hline \multicolumn{2}{|l|}{ Support from groups } & 0 \\
\hline \multicolumn{2}{|c|}{$\begin{array}{l}\text { 2. In the last } 12 \text { months, did you receive from the group any emotional help, economic help or assistance in helping you know or } \\
\text { do things? }\end{array}$} & 1 \\
\hline
\end{tabular}
do things?

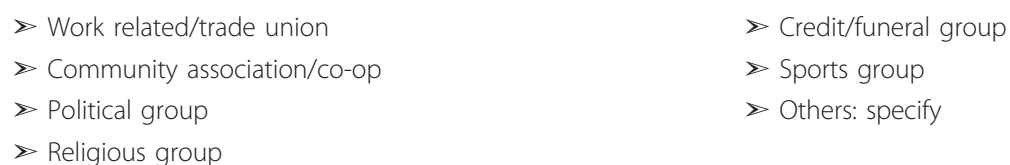

3. In the last 12 months, have you received any help or support from any of the following, this can be emotional help, economic 1 help or assistance in helping you know or do things?

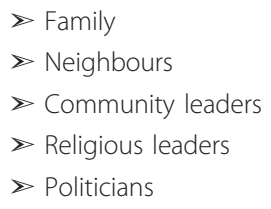

*Total score of four questions of cognitive social capital: 2 or less $=$ low, 3 or $4=$ high 
with my life, 4) So far I have gotten the important things I want in life, and 5) If I could live my life over, I would change almost nothing. The total score of SWLS ranged from 5 to 35 , which we treated as a continuous variable. A high score was interpreted as high life satisfaction. Good internal consistency was observed with a Cronbach alpha coefficient of .87 , which was close to .85 reported by the scale developers [26].

\section{Socio-economic and disability-related factors}

We measured socio-economic factors and disabilityrelated factors as possible confounders. Socio-economic factors included age, sex, number of family members living with the participant, marital status, educational level, job status, individual income status, and war experience. Disability-related factors in this study were number of years with impairment, timing of commencement of impairment, number of impaired body part(s), and level of independence with respect to activities of daily living (ADL), indoor moving status, and outdoor moving status. We divided impaired body parts into six: neck, trunk, upper right limb, upper left limb, lower right limb, and lower left limb. Regarding ADL, we used the Barthel Index [29] which consists of 10 ADL-related items such as level of independence in toilet use, bathing, and dressing. We coded those who had a maximum score on the Barthel Index as 'independent' and the others as 'with help,' respectively. With regard to indoor moving status and outdoor moving status, we coded those who never used any assistive device or someone's help as 'independent.' On the other hand, those who used either or both of them were coded as 'with help.'

\section{Statistical analysis}

We conducted two kinds of statistical analysis. First, we performed bivariate tests including independent-samples t-test and one-way analysis of variance (ANOVA) to explore the crude association between life satisfaction and all variables. Then, we ran a standard multiple regression to control for confounding effects. In the regression model, we included all social capital variables and the variables with $p$-values of less than .10 from the bivariate analysis. We treated the social capital variables except for 'citizenship activities' and ADL as continuous variables unlike in bivariate tests. SPSS version 16.0 for Windows (SPSS Inc., Chicago, IL) was used for all statistical analyses.

\section{Results}

\section{Characteristics of the participants}

Table 2 shows the characteristics of the 136 participants by gender. The mean age was 36 (SD 13.3) years old. All study participants were literate and $31(22.8 \%)$ had graduated from a university. One hundred and seven (78.7\%) had a job such as bicycle repair and shop
Table 2 Characteristics of the participants $(n=136)$ *

\begin{tabular}{|c|c|c|c|}
\hline \multicolumn{2}{|l|}{ Variable } & $\begin{array}{c}\text { Male }(n= \\
68) \\
n(\%)\end{array}$ & $\begin{array}{c}\text { Female }(n= \\
68) \\
n(\%)\end{array}$ \\
\hline \multicolumn{4}{|l|}{$\begin{array}{l}\text { Socio-economic } \\
\text { variable }\end{array}$} \\
\hline Age & Mean (SD) & $38.3(14.7)$ & $33.5(11.4)$ \\
\hline$n$ of family members & Mean (SD) & $4.5(2.3)$ & $4.0(2.1)$ \\
\hline \multirow[t]{3}{*}{ Marital status } & Single & $31(45.6)$ & $49(72.1)$ \\
\hline & Married & $30(44.1)$ & $9(13.2)$ \\
\hline & Others $^{\dagger}$ & $5(7.4)$ & $6(8.8)$ \\
\hline \multirow[t]{3}{*}{ Educational level } & $\begin{array}{l}<\text { High } \\
\text { school }\end{array}$ & $27(39.7)$ & $25(36.8)$ \\
\hline & High school & $21(30.9)$ & $22(32.4)$ \\
\hline & University & $16(23.5)$ & $15(22.1)$ \\
\hline \multirow[t]{2}{*}{ Job } & Yes & $52(76.5)$ & $55(80.9)$ \\
\hline & No & $16(23.5)$ & $13(19.1)$ \\
\hline \multirow[t]{2}{*}{ Regular income } & Yes & $40(58.8)$ & $40(58.8)$ \\
\hline & No & $27(39.7)$ & $25(36.8)$ \\
\hline \multirow[t]{2}{*}{ War experience } & Yes & $8(11.8)$ & $1(1.5)$ \\
\hline & No & $58(85.3)$ & $66(97.1)$ \\
\hline \multicolumn{4}{|l|}{$\begin{array}{c}\text { Disability-related } \\
\text { variable }\end{array}$} \\
\hline Impaired years & Mean (SD) & $24.4(14.7)$ & $25.8(13.1)$ \\
\hline \multirow[t]{2}{*}{ Timing of impairment } & At birth & $24(35.3)$ & 19 (27.9) \\
\hline & Later & $43(63.2)$ & $46(67.6)$ \\
\hline \multirow[t]{2}{*}{$n$ of impaired part ${ }^{\ddagger}$} & 1 & $32(47.1)$ & $34(50.0)$ \\
\hline & 2 or more & $36(52.9)$ & $34(50.0)$ \\
\hline \multirow[t]{2}{*}{ Activities of daily living } & Independent & $47(69.1)$ & $43(63.2)$ \\
\hline & With help & $15(22.1)$ & $12(17.6)$ \\
\hline \multirow[t]{2}{*}{ Indoor moving status } & Independent & $42(61.8)$ & $45(66.2)$ \\
\hline & With help & $25(36.8)$ & $21(30.9)$ \\
\hline \multirow[t]{2}{*}{ Outdoor moving status } & Independent & $28(41.2)$ & $32(47.1)$ \\
\hline & With help & 37 (54.4) & 36 (52.9) \\
\hline
\end{tabular}

* Missing cases are not shown in this table.

${ }^{+}$Widowed or divorced

" Impaired parts were divided into six: neck, trunk, upper right limb, upper left limb, lower right limb, and lower left limb.

assistant, and $80(58.8 \%)$ had a regular job or lived on a pension, which provides regular income. The causes of participants' impairments varied such as polio, angiopathy, and injury by traffic accidents or war; accordingly, types of impairment varied such as deformation, amputation, and paralysis. Of the total, $43(31.6 \%)$ were disabled at birth, and 70 (51.5\%) had two or more disabled parts. Ninety $(66.2 \%)$ who had the maximum score of the Barthel Index did not need any help with ADL.

\section{Life satisfaction of persons with musculoskeletal impairments}

In the binary analysis, we found significant associations between several variables and life satisfaction. As shown in Table 3, educational level $(p=.009)$ was significantly associated with life satisfaction. Those with high 
Table 3 Association between socio-economic and disability-related variables and life satisfaction

\begin{tabular}{|c|c|c|c|c|}
\hline \multicolumn{2}{|l|}{ Variable } & \multirow{2}{*}{$\begin{array}{c}\text { Mean* }^{*} \\
17.5\end{array}$} & \multirow{2}{*}{$\begin{array}{l}\text { SD } \\
6.3\end{array}$} & \multirow{2}{*}{$\begin{array}{c}\boldsymbol{p}^{\boldsymbol{\dagger}} \\
.208\end{array}$} \\
\hline Age & $<30$ & & & \\
\hline & $30-39$ & 15.3 & 6.7 & \\
\hline & $40-49$ & 15.4 & 4.5 & \\
\hline & $>49$ & 18.1 & 5.0 & \\
\hline \multirow[t]{2}{*}{ Sex } & Male & 16.8 & 6.0 & .744 \\
\hline & Female & 17.2 & 5.9 & \\
\hline \multirow[t]{3}{*}{ Educational level } & $<$ High school & 15.3 & 4.9 & .009 \\
\hline & High school & 16.7 & 4.9 & \\
\hline & University & 19.4 & 7.8 & \\
\hline \multirow[t]{2}{*}{ Job } & Yes & 17.2 & 5.9 & .484 \\
\hline & No & 16.3 & 6.0 & \\
\hline \multirow[t]{2}{*}{ Regular income } & Yes & 17.5 & 6.0 & .177 \\
\hline & No & 16.0 & 5.8 & \\
\hline \multirow[t]{2}{*}{ Activities of daily living } & Independent & 17.7 & 5.9 & .013 \\
\hline & With help & 14.4 & 5.7 & \\
\hline \multirow[t]{2}{*}{ Indoor moving status } & Independent & 18.0 & 6.0 & .015 \\
\hline & With help & 15.3 & 5.5 & \\
\hline \multirow[t]{2}{*}{ Outdoor moving status } & Independent & 18.1 & 5.7 & .086 \\
\hline & With help & 16.3 & 6.1 & \\
\hline
\end{tabular}

* Mean score of the Satisfaction with Life Scale (SWLS)

+ One-way analysis of variance (ANOVA) for age and educational level; independent-samples t-test for other variable

education, especially the university graduates, were more likely to have higher life satisfaction. Regarding disability-related factors, $\operatorname{ADL}(p=.013)$ and indoor moving status $(p=.015)$ were significantly associated with life satisfaction. Those who were physically independent were inclined to have higher life satisfaction.

Table 4 demonstrates the association between social capital and life satisfaction. Out of the five items of structural social capital, 'group membership' $(p<.001)$ and 'support from groups' $(p=.048)$ were significantly associated with life satisfaction. Those who were active members of two or more groups had higher life satisfaction than those who actively participated in only one group or who did not actively participate in any groups. Similarly, those who received support from two or more groups were inclined to have higher life satisfaction. Regarding the four items of cognitive social capital, 'sense of belonging' ( $p=.017)$ to their community was observed as a significant contributor to high life satisfaction. The one hundred and seven participants $(78.7 \%)$ who felt themselves to be a part of their community were more likely to have higher life satisfaction.

Table 5 shows the result of the multiple regression analysis. Since multicolinearity was found between 'group membership' and 'support from groups' (Pearson's correlation $=.728)$, we excluded 'support from groups' from the regression model. The model's $\mathrm{R}^{2}$ was .233 , and the significance of the model was confirmed with ANOVA ( $p$
Table 4 Association between social capital components and life satisfaction

\begin{tabular}{|c|c|c|c|c|c|}
\hline \multicolumn{2}{|l|}{ Variable } & \multirow{2}{*}{$\begin{array}{c}n(\%) \\
44(32.4)\end{array}$} & \multirow{2}{*}{$\begin{array}{c}\begin{array}{c}\text { Mean } \\
*\end{array} \\
16.0\end{array}$} & \multirow{2}{*}{$\begin{array}{r}\text { SD } \\
3.7\end{array}$} & \multirow{2}{*}{$\begin{array}{c}p^{\dagger} \\
<.001\end{array}$} \\
\hline Group membership & 0 & & & & \\
\hline & 1 & $58(42.6)$ & 16.0 & 6.2 & \\
\hline & 2 or more & $27(19.9)$ & 20.9 & 6.7 & \\
\hline \multirow[t]{3}{*}{ Support from groups } & 0 & $57(41.9)$ & 16.4 & 4.8 & .048 \\
\hline & 1 & $51(37.5)$ & 16.5 & 5.8 & \\
\hline & 2 or more & $21(15.4)$ & 19.9 & 7.8 & \\
\hline \multirow{3}{*}{$\begin{array}{l}\text { Supports from } \\
\text { individuals }\end{array}$} & 0 & $27(19.9)$ & 15.4 & 3.4 & .183 \\
\hline & 1 & $35(25.7)$ & 16.6 & 5.3 & \\
\hline & 2 or more & $67(49.3)$ & 17.9 & 6.8 & \\
\hline \multirow[t]{3}{*}{ Citizenship activities } & None & $48(39.7)$ & 16.6 & 6.5 & .628 \\
\hline & $\begin{array}{l}\text { Joined or } \\
\text { talked }\end{array}$ & $17(14.0)$ & 17.2 & 7.3 & \\
\hline & $\begin{array}{l}\text { Joined \& } \\
\text { talked }\end{array}$ & $56(46.3)$ & 17.8 & 4.9 & \\
\hline \multirow[t]{2}{*}{ Joined with others } & Yes & $64(47.1)$ & 17.8 & 4.9 & .335 \\
\hline & No & $59(43.4)$ & 16.7 & 6.7 & \\
\hline \multirow[t]{2}{*}{ Talked with authorities } & Yes & $67(49.3)$ & 17.6 & 5.5 & .428 \\
\hline & No & $55(40.4)$ & 16.8 & 6.4 & \\
\hline \multirow[t]{2}{*}{ Cognitive social capital } & Low & $22(18.5)$ & 15.6 & 4.5 & .133 \\
\hline & High & $97(81.5)$ & 17.7 & 6.2 & \\
\hline \multirow[t]{2}{*}{ Trust } & Yes & $99(72.8)$ & 17.5 & 6.2 & .217 \\
\hline & No & $24(17.6)$ & 16.3 & 3.9 & \\
\hline \multirow[t]{2}{*}{ Social harmony } & Yes & $97(71.3)$ & 17.4 & 6.1 & .681 \\
\hline & No & $26(19.1)$ & 16.9 & 4.9 & \\
\hline \multirow[t]{2}{*}{ Sense of belonging } & Yes & $\begin{array}{c}107 \\
(78.7)\end{array}$ & 17.7 & 5.9 & .017 \\
\hline & No & $14(10.3)$ & 13.6 & 5.2 & \\
\hline \multirow[t]{2}{*}{ Sense of fairness ${ }^{\ddagger}$} & Yes & $19(14.0)$ & 16.5 & 4.5 & .531 \\
\hline & No & $\begin{array}{c}103 \\
(75.7)\end{array}$ & 17.4 & 6.1 & \\
\hline
\end{tabular}

* Mean score of the Satisfaction with Life Scale (SWLS)

+ One-way analysis of variance (ANOVA) for group membership, support from groups, support from individuals, and citizenship activities; independentsamples t-test for other variables

₹ This variable was reverse coded so 'No' indicates more social capital.

$=.012$ ). As a result, only 'group membership' was significantly associated with life satisfaction (Standardized Beta $=.26, \mathrm{t}=2.01, p=.041)$. The effect of other variables was considerably weakened although 'educational level (university)' remained close to the significant level (Standardized Beta $=.24, \mathrm{t}=1.82, p=.073$ ).

\section{Discussion}

Structural social capital and life satisfaction of persons with musculoskeletal impairments

In this study, one of the structural social capital components, 'group membership,' was significantly associated with life satisfaction even after controlling for confounding factors. Specifically, being an active member of two or more groups was associated with higher life 
Table 5 Multiple linear regression predicting life satisfaction by social capital components and significant variables* $(n=92)$

\begin{tabular}{|c|c|c|c|c|c|}
\hline \multirow[t]{3}{*}{ Variable } & \multicolumn{5}{|c|}{ Multiple regression $\left(R^{2}=0.233\right)$} \\
\hline & \multicolumn{2}{|c|}{ Unstandardized Coefficient } & Standardized Coefficient & \multirow[b]{2}{*}{$\mathbf{t}$} & \multirow[b]{2}{*}{$p$} \\
\hline & B & SE & Beta & & \\
\hline \multicolumn{6}{|l|}{ Social capital $^{\dagger}$} \\
\hline Group membership $^{\ddagger}$ & 1.73 & 0.83 & .26 & 2.01 & .041 \\
\hline Support from individuals ${ }^{\ddagger}$ & -0.08 & 0.53 & -.02 & -0.15 & .879 \\
\hline \multicolumn{6}{|l|}{ Citizenship activities } \\
\hline None & & & Reference & & \\
\hline Joined or talked & -1.10 & 1.94 & -.06 & -0.57 & .573 \\
\hline Joined and talked & 1.57 & 1.47 & .12 & 1.07 & .289 \\
\hline 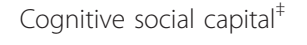 & 0.64 & 0.67 & .10 & 0.95 & .347 \\
\hline \multicolumn{6}{|l|}{ Socio-economic factor } \\
\hline \multicolumn{6}{|l|}{ Educational level } \\
\hline$<$ High school & & & Reference & & \\
\hline High school & 1.04 & 1.64 & .08 & 0.64 & .527 \\
\hline University & 3.22 & 1.78 & .24 & 1.82 & .073 \\
\hline \multicolumn{6}{|l|}{ Disability-related factors } \\
\hline Activities of daily living ${ }^{\ddagger}$ & 0.56 & 0.54 & .12 & 1.03 & .304 \\
\hline \multicolumn{6}{|l|}{ Indoor moving status } \\
\hline With help & & & Reference & & \\
\hline Independent & 2.35 & 2.01 & .17 & 1.17 & .246 \\
\hline \multicolumn{6}{|l|}{ Outdoor moving status } \\
\hline With help & & & Reference & & \\
\hline Independent & -0.93 & 1.63 & -.07 & -0.57 & .570 \\
\hline
\end{tabular}

* Variables with $p$-values less than .10 in binary analysis

' 'Support from groups' was excluded from the regression model due to multicolinearity with 'group membership.'

₹ Continuous variables

satisfaction. This finding indicates that the number of groups to which an individual actively belongs could differentiate the life satisfaction. Those who had higher life satisfaction were active members of not only disabled people's groups but also other types of groups, such as religious groups and sports groups. Being an active member of these groups in addition to disabled people's groups could lead to higher life satisfaction. In contrast, those who thought they were not active members of any group and those who thought they were active members of only one group were more likely to have lower life satisfaction. Furthermore, this finding can be interpreted as showing a positive effect of social participation on life satisfaction. Persons with musculoskeletal impairments are more likely to be socially isolated because of their impairments and a potentially unfriendly environment around them, such as physical barriers to access or personal prejudice [30]. Whether persons with musculoskeletal impairments can participate in society through group activities, therefore, can significantly affect their life satisfaction.

Other components of structural social capital such as 'support from individuals' and 'citizenship activities' were not significantly associated with life satisfaction. Although direct evidence is lacking, we interpret these results as follows. Regarding 'support from individuals,' the term 'support' might have been understood narrowly by persons with musculoskeletal impairments. Our participants received physical support from others to the extent that they needed it. That situation might have caused them to think that 'support' meant just physical support. As for 'citizenship activities,' the inaccessibility to citizenship activities in Vietnam should be reconsidered [31]. In Vietnam, it is essential for citizens to have a connection with authorities such as head members of the Communist Party to make any action in their community. The participants who did not have any personal connection with authorities could have an opportunity to meet with authorities in certain official meetings which attached great importance to formality. However, they might know that the discussion in those meetings meant a little compared to personal connection with authorities. Similarly, distinct administrative division of community builds a barrier between communities. De Silva et al. [32] have pointed out the low level of 'citizenship activities' in Vietnam, especially related to 
talking to the authorities. Persons with musculoskeletal impairments could unilaterally make a decision related to 'group membership;' however, participation in 'citizenship activities' requires the willingness of others to collaborate. This difference may explain why 'citizenship activities' did not affect life satisfaction.

\section{Cognitive social capital and life satisfaction of persons with musculoskeletal impairments}

Cognitive social capital plays a crucial role in mental health [33]; however, none of the cognitive social capital components were significant in our multiple regression analysis. Since cognitive social capital is related to one's subjective perception of the community, the term 'community' should be carefully defined. While we defined the term 'community' as the official commune in Vietnam, the perception of the official commune might be different from the 'community' especially in persons with musculoskeletal impairments. For example, we measured a sense of belonging to the community with the question 'Do you feel as though you are really a part of this community?'. However, persons with musculoskeletal impairments could feel a sense of belonging not only to the official commune but also to various types of informal communities. For instance, the virtual community of the Internet might be important because of its greater ease of access for some persons with musculoskeletal impairments [34]. To assess the actual impact of cognitive social capital on the life satisfaction of persons with musculoskeletal impairments, the appropriate definition of the term 'community' should be carefully considered.

\section{Educational level and life satisfaction of persons with musculoskeletal impairments}

Persons with musculoskeletal impairments may face difficulties in continuing their education due to inaccessibility and discrimination [30]. The literacy rate has reached over 90\% in Vietnam [22,35]; however, it is still not known how many persons with or without musculoskeletal impairments do not go to university and for what reasons. In Vietnam, universities provide useful opportunities for social participation. For example, two out of nine disabled people's groups that we targeted in this study were university-based, and the majority of members of those two groups were talked into joining the groups by peers in the same university. Although we did not find a significant association between educational level and life satisfaction in our multiple regression analysis probably because people with high education were likely to have more opportunities to participate in various groups such as sports group in university, equal access to higher education for persons with musculoskeletal impairments remains an important factor in their social participation.

\section{Limitations}

The findings of this study, however, should be interpreted carefully. First, this study did not consider whether a participant could recover from the musculoskeletal impairment. Most participants were living with musculoskeletal impairments that were medically stable but likely permanent. Social factors may play a different role among persons with recoverable musculoskeletal impairments because they tend to focus more on medical factors. Second, this study was conducted only with the members of disabled people's groups in the capital city. Therefore, caution is needed to generalize our findings to the other populations such as persons without musculoskeletal impairments, persons with musculoskeletal impairments who do not belong to any group, and persons with musculoskeletal impairments in rural area. Third, our analysis does not show the relationship between specific combinations of groups and life satisfaction since it included data on the actual number of groups each participant actively participate in without making any combinations of groups. Fourth, this study was a cross-sectional study which cannot clarify the actual causality. Although we found a significant association between particular variables and life satisfaction, we must use additional research methods such as case studies and in-depth interviews, and further longitudinal studies are necessary to clarify the impact of social capital on life satisfaction.

\section{Conclusions}

Despite these limitations, the study findings are relevant because we revealed the importance of social aspects of disability with quantitative data. In addition, this was the first social capital study to target persons with musculoskeletal impairments in Vietnam. We expect our findings could be leverage to improve the social situation of persons with musculoskeletal impairments especially in developing countries. The findings suggest the importance of considering an active membership of two or more groups to increase the life satisfaction of persons with musculoskeletal impairments. To encourage persons with musculoskeletal impairments to have multiple active memberships, their access to groups should be encouraged and enhanced. For example, information about community groups should be available in various formats such as via the Internet, and the meeting places should be easily accessible to persons with any type of musculoskeletal impairment. Furthermore, group members should make reasonable accommodation to welcome persons with musculoskeletal impairments in 
their group. Without adequate accessibility, persons with musculoskeletal impairments cannot participate in group activities no matter how highly they are motivated.

\section{Acknowledgements}

This study was conducted with the cooperation of the Hanoi School of Public Health (HSPH). We especially thank Ms. Dang Thi Ha Trang from the Department of Rehabilitation, HSPH, and Mr. Nguyen Hoai Duc from the National Coordinating Committee on Disability in Vietnam (NCCD) for their warm support.

\section{Author details}

${ }^{1}$ Department of Community and Global Health, Graduate School of Medicine, the University of Tokyo, 7-3-1 Hongo, Bunkyo-ku, Tokyo, Japan.

${ }^{2}$ Department of Rehabilitation, Hanoi School of Public Health, 138 Giang Vo Str., Hanoi, Vietnam.

\section{Authors' contributions}

$K T$ conceived the research questions, designed the study, conducted preparatory field works, collected data, analyzed data, and drafted the manuscript for publication. NTMT was involved in revisions of the research proposal, preparatory field works, and data collection. KCP was involved in revisions of the research proposal, data analysis, and revisions of the manuscript for publication. KS was involved in revisions of the research proposal, data analysis, and revisions of the manuscript for publication. MJ was involved in revisions of the research proposal, data analysis, and revisions of the manuscript for publication. JY was involved in revisions of the research proposal, data analysis, and revisions of the manuscript for publication. All authors read and approved the final manuscript.

\section{Competing interests}

The authors declare that they have no competing interests.

Received: 5 October 2010 Accepted: 1 April 2011 Published: 1 April 2011

\section{References}

1. Oliver M: The politics of disablement London: Mecmillan; 1990

2. World Health Organization: International classification of functioning, disability, and health Geneva: WHO; 2001.

3. United Nations: Convention on the rights of persons with disabilities New York: UN; 2006 [http://www.un.org/disabilities/].

4. United Nations Economic and Social Commission for Asia and Pacific: Disability at a glance: a profile of 28 countries and areas in Asia and the Pacific New York: United Nations Publication; 2006.

5. World Health Organization: Global programming note 2005-2007: call for resource mobilization Copenhagen: WHO Regional Office for Europe; 2005.

6. World Health Organization: Social determinants of health: the solid facts Copenhagen: WHO Regional Office for Europe; 2003.

7. Kawachi I, Subramanian SV, Kim D: Social capital and health Springer Science + Business Media: Berlin; 2008.

8. Putnam RD: Making democracy work Princeton: Princeton University Press; 1993.

9. De Silva MJ, Harpham T, Tuan T, Bartolini R, Penny ME, Huttly SR: Psychometric and cognitive validation of a social capital measurement tool in Peru and Vietnam. Soc Sci Med 2006, 62: 941-53.

10. Uphoff $\mathrm{N}$ : Understanding social capital: learning from the analysis and experience of participation. In Social capital: a multifaceted perspective. Edited by: Dasgupta P, Serageldin I. Washington DC: The World Bank; 1999: 215-49.

11. Krishna A, Shrader E: Cross-cultural measures of social capital: A tool and results from India and Panama Washington DC: The World Bank; 2000.

12. Kawachi I, Kennedy BP, Glass R: Social capital and self-rated health: a contextual analysis. Am J Public Health 1999, 89: 1187-93.

13. Helliwell JF, Putnam RD: The social context of well-being. Philosophical Transactions B 2004, 359: 1435-46.

14. Bjornskov C: The happy few: cross-county evidence on social capital and life satisfaction. KYKLOS 2003, 56: 3-16.
15. Pavot W, Diener E, Colvin CR, Sandvik E: Further validation of the Satisfaction With Life Scale: evidence for the cross-method convergence of well-being measures. J Pers Assess 1991, 57: 149-61.

16. Andrews FM, Robinson JP: Measures of subjective well-being. In Measures of personality and social psychological attitudes. Edited by: Robinson JP, Shaver PR, Wrightsman LS. California: Academic Press; 1991: 61-114.

17. McDowell I, Newell C: Measuring health: a guide to rating scales and questionnaires Oxford: Oxford University Press; 1996.

18. Putzke JD, Richards JS, Hicken BL, De Vivo MJ: Predictors of life satisfaction: a spinal cord injury cohort study. Arch Phys Med Rehabil 2002, 83: 555-61.

19. Craig A, Tran Y, Middleton J: Psychological morbidity and spinal cord injury: a systematic review. Spinal Cord 2008, 1-7.

20. Van Koppenhagen CF, Post MW, Van der Woude LH, et al: Changes and determinants of life satisfaction after spinal cord injury: a cohort study in the Netherlands. Arch Phys Med Rehabil 2008, 89: 1733-40.

21. Disability: beyond the medical model. Lancet 2009, 374: 1793, Editorial.

22. Ministry of Health: Vietnam health report 2006 Hanoi: Medical Publishing House; 2006

23. Harpham T, De Silva M, Jones N, Garlick C: Maternal social capital and child wellbeing in comparative perspective London: Young Lives; 2006.

24. Harpham T, Grant E, Thomas E: Measuring social capital within health surveys: key issues. Health Policy Plan 2002, 17: 106-11.

25. Tuan T, Harpham T: Validity of a social capital measurement tool in Vietnam. Asian J Soc Sci 2005, 33: 208-22.

26. Diener E, Emmons RA, Larsen RJ, Griffin S: The satisfaction with life scale. $J$ Pers Assess 1985, 49: 71-5.

27. Pavot W, Diener E, Colvin CR, Sandvik E: Further validation of the Satisfaction With Life Scale: evidence for the cross-method convergence of well-being measures. J Pers Assess 1991, 57: 149-61.

28. Hultell D, Gustavsson JP: A psychometric evaluation of the Satisfaction of Life Scale in a Swedish nationwide sample of university students. Pers Individ Dif 2008, 44: 1070-9.

29. Mahoney Fl, Barthel DW: Functional evaluation: The Barthel Index. Md State Med J 1965, 14: 56-61.

30. United Nations Children's Fund: Promoting the rights of children with disabilities Florence; UNICEF Innocenti Research Centre; 2007.

31. Amnesty International: Amnesty International report 2008: the state of the world's human rights London: Amnesty International Publications; 2008.

32. De Silva MJ, Harpham T: Maternal social capital and child nutritional status in four developing countries. Health Place 2007, 13: 341-55.

33. De Silva MJ, McKenzie K, Harpham T, A Huttly SR: Social capital and mental illness: a systematic review. J Epidemiol Community Health 2005, 59: 619-27.

34. Larkin M: Web gears up for people with disabilities. Lancet 2000, 356: 142

35. United Nations Educational, Scientific and Cultural Organization: Education for all global monitoring report 2009 Oxford; Oxford University Press; 2008.

\section{Pre-publication history}

The pre-publication history for this paper can be accessed here: http://www.biomedcentral.com/1471-2458/11/206/prepub

doi:10.1186/1471-2458-11-206

Cite this article as: Takahashi et al: Social capital and life satisfaction: a cross-sectional study on persons with musculoskeletal impairments in Hanoi, Vietnam. BMC Public Health 2011 11:206. 